\title{
COMMENTARY/LETTER
}

\section{The Decade of Vaccines: An Opportunity to Prioritize Data Collection, Analysis and Use within National Immunisation Programmes}

\author{
David W. Brown* \\ United Nations Children's Fund, Three United Nations Plaza, New York, 10017 USA
}

\begin{abstract}
Despite remarkable improvement in global immunisation coverage during the past 30 years, progress has not been uniform. The reasons underlying sub-optimal progress are many, but perhaps one of the most important and overlooked is that national immunisation programmes too often have not received the appropriate support and tools to facilitate the gathering, managing, analysing and reporting of data in a manner that enables taking action to ensure quality and sustainability of the programme. However, it is not only an issue of lacking capacity within these programmes, but also one of political will and commitment to invest in data collection, data management, analysis and reporting. The Decade of Vaccines provides a unique opportunity to highlight the importance and increase support of data and information systems that feed the sound evidence base needed to move global immunsation forward during the next ten years.
\end{abstract}

Keywords: Immunization programs, information systems, statistics, collection, data, interpretation, statistical data, data analysis, statistical.

\section{INTRODUCTION}

Millennium Development Goal (MDG) 4 calls for a twothirds reduction of under-five mortality by 2015 . National immunisation programmes are one of the pillars on which much of the success towards MDG 4 rests [1]. Though much progress has been achieved since the launch of the Expanded Programme on Immunisation in 1974 [2], if we are clear sighted in our vision for the future of global immunisation, we will acknowledge that there is much room for improvement. Central to improving the future of immunisation programmes worldwide is good science and a sound evidence base. This includes information on the impact of vaccination strategies supported by timely, robust and relevant data, the most basic of which include the number of children vaccinated and the target population at national and sub-national levels. Unfortunately for many national immunisation programmes, meeting this challenge is akin to being adrift at sea without a compass.

National immunisation programmes have been charged with the delivery and maintenance of one of the most important public health interventions to date. Remarkable strides have been made during the past 30 years (i.e., coverage with three doses of diphtheria- tetanus -pertussis vaccine [DTP3] increased from $20 \%$ in 1980 to $75 \%$ in 1990 to $82 \%$ in 2009) $[3,4]$; however, progress has not been uniform. The reasons underlying sub-optimal progress are many, but perhaps one of the most important and overlooked is that immunisation programmes too often have not received the appropriate

*Address correspondence to this author at the United Nations Children's Fund, Three United Nations Plaza, New York, 10017 USA;

Tel: +1.212.303.79.88; E-mail: dbrown @ unicef.org support and tools to facilitate the gathering, managing, analysing and reporting of data in a manner that enables taking action to ensure quality and sustainability of the programme. Indeed, immunisation programmes collect data daily. Indeed, guidance manuals have been developed and distributed. But, many national immunisation programmes continue to struggle with conducting representative immunisation coverage surveys. At facility levels, coverage data are often not collected in a fashion that enables disaggregation (e.g., by service delivery). And, all too often programme staff are challenged when planning and targeting interventions and managing stocks due to incomplete, inaccurate or entirely lacking vital registration data for the target population. As a result, staff are forced to resort to a variety of different strategies, including guess work! By improving the quality and completeness of data on the number of children vaccinated and the underlying target population, guess work is removed and more effective and efficient immunisation programmes are possible.

Despite calls-to-action [5] focused on strengthening data and capacity to collect, analyze and use data and frameworks [6] for providing the evidence essential for informed decision-making, widespread challenges persist. Within national immunisation programmes, the lack of up-to-date and relevant data often reflects not the difficulties of data collection, but rather the significant discrepancy between the resources invested in high quality data collection in some areas (e.g., finance, trade), and lack of data in others (e.g., health). In other words, it is not only an issue of lacking capacity within national immunisation programmes (and other health programmes) but also one of political will and commitment to invest in data collection, data management, analysis and reporting. When statistics are a priority, even if it is difficult to 
collect accurate information, they are there. One needs to look no further than financial statistics, such as national income and inflation, for such examples. Such data are not easy to collect as they require detailed and rapidly updated economic information, yet they are available almost universally - even in the poorest countries.

Planning for the so-called Decade of Vaccines [7], one of the largest single commitments in global health to-date, is ongoing. In addition to supporting innovation in vaccine research and development and scaling-up the delivery of lifesaving vaccines, the Decade of Vaccines also provides a unique opportunity to prioritize long-term and sustained commitments by donor organisations and national governments in timely, robust and relevant data and to develop and maintain national and sub-national capacity for data collection, analysis and data use to build a sound evidence base on which to make informed programme and policy decisions. Notwithstanding the data limitations for some immunisation programmes, the experiences in many countries underscore the fact that investments in these programmes yield high returns; but, the performance and sustainability of many immunisation programmes remain fragile as we enter the next decade and beyond. An opportunity is at hand to provide national immunisation programmes a compass to help navigate the vision for global immunisation with a renewed focus on data and information systems supporting surveillance and monitoring that will undoubtedly result in improved service delivery and ultimately in improved health outcomes for children worldwide.

\section{DISCLAIMER}

The opinions expressed herein are those of the author alone and do not necessary reflect those of the United Nations Children's Fund.

\section{CONFLICT OF INTEREST}

None to be noted.

\section{ACKNOWLEDGEMENTS}

The author wishes to thank Drs. Jos Vandelear, Tony Burton and Ms. Stacy Young for comments and editorial assistance on previous versions of this work.

\section{REFERENCES}

[1] van den Ent, M.; Brown, D.W.; Hoekstra, E.J.; Strebel, P.M.; Christie, A.; Dabbagh, A.A.; Cochi, S.L. Measles mortality reduction contributes significantly to reduction of all cause mortality among children less than five years of age. J. Infect. Dis., 19902008, In Press.

[2] Bland, J.; Clements, J. Protecting the world's children: the story of WHO's immunization programme. World Health Forum, 1998, 19 162-173.

[3] Burton, A.H.; Monasch, R.; Lautenbach, B.; Gacic-Dobo, M.; Neill, M.; Karimov, R.; Wolfson, L.; Jones, G.; Birmingham, M. WHO and UNICEF estimates of national infant immunization coverage: methods and processes. Bull. World Health Organ, 2009, $87,535-541$.

[4] WHO and UNICEF Estimates of National Immunization Coverage, 2010. Available on the web at http://www.childinfo.org/ immunization.html or http://www.who.int/immunization_monitoring/ data/en/ (accessed on 30 December 2010).

[5] Chan, M.; Kazatchkine, M.; Lob-Levyt, J.; Obaid, T.; Schweizer, J.; Sidibe, M.; Veneman, A.; Yamada, T. Meeting the Demand for Results and Accountability: A Call for Action on Health Data from Eight Global Health Agencies. PLoS. Med., 2010, 7(1), e1000223.

[6] Dabbagh, A.; Eggers, R.; Cochi, S.; Dietz, V.; Strebel, P.; Cherian, T. A new global framework for immunization monitoring and surveillance. Bull. World Health Organ, 2007, 85(12), 904-905.

[7] Gates Foundation's decade of vaccines. Lancet Infect. Dis., 2010, $10,139$. 